\title{
Role of controlled breathing in adaptation to high altitude
}

\author{
Aghajanyan Siranush, Karapetyan Marietta, Adamyan Nonna, Amiryan Silva*
}

Dept. of Human\&Animal Physiology, Yerevan State University (YSU), Yerevan, Armenia

Email address:

samiryan@fulbrightmail.org(A. Silva)

\section{To cite this article:}

Aghajanyan Siranush, Karapetyan Marietta, Adamyan Nonna, Amiryan Silva. Role of Controlled Breathing in Adaptation to High Altitude. American Journal of BioScience. Vol. 1, No. 1, 2013, pp. 16-23. doi: 10.11648/j.ajbio.20130101.14

\begin{abstract}
Possibilities for adaptation to high altitude conditions by the method of controlled breathing are investigated. It is determined that voluntary reduction in respiratory rate (to 6 per minute) among school students living in highlands improves the heart functioning. It identifies the possibility to correct the disturbances revealed during the investigation through the method of controlled breathing.
\end{abstract}

Keywords: Adaptation to High Altitude, Respiratory Rate, Cardiovascular System, Controlled Breathing

\section{Introduction}

In recent years, there has been an increasing population living at high altitude (HA) due to immigration, work duty or tourism. With an increasing population living at a high altitude, the impact of high altitude residence on human cardiovascular functions has raised concerns [1].

Normal activity of the respiratory system ensures the biochemical and physiological processes in the body. The respiration cycle is an intermittent process repeated during whole life. Its role is not limited to oxygen inspiration and assimilation, and carbon dioxide expiration. Respiration also regulates the rate of oxidative reactions, the work of cardiovascular system, the course of energetic metabolism, the synthesis of ATP etc.

The overall purpose of the respiratory system is to provide oxygen for metabolism and eliminate the carbon dioxide produced. In the steady equilibrium state oxygen intake into the lungs is matched to oxygen consumption by the tissues, and carbon dioxide elimination in the lungs is matched to carbon dioxide production by the tissues.

The respiratory control system accomplishes this goal by adjusting pulmonary ventilation. The partial pressure of oxygen is kept at a level sufficient for tissue metabolism. The partial pressure of carbon dioxide in the tissues is kept at a level that ensures the maintenance of hydrogen ion concentrations within the limits necessary for protein function.

The regulation of respiration is a complex circuit of different processes. It may be influenced by oxygen and carbon dioxide content in atmosphere, by barometric pressure, by different pathological activities in the body etc.
The most important in humoral regulation of respiration is the tension (partial pressure) of oxygen $\left(\mathrm{PaO}_{2}\right)$ and carbon dioxide $\left(\mathrm{PaCO}_{2}\right)$ in arterial blood, but the interaction of these two components is quite complicated.

The influence of arterial $\mathrm{CO}_{2}$ partial pressure on cerebral auto regulation (CA) is well known. It has been characterized in the frequency domain [2]. The $\mathrm{PaO}_{2}$ also affects the breathing rate and oxygen assimilation. The deficiency of oxygen in the body may lead to hypoxia.

Nowadays due to the scientific and technical progress, air pollution increase, climate change, wide consumption of tobacco and allergy there is an increase in the numbers of conditions related to respiratory system. The most frequent conditions related to the respiratory system are: acute laryngitis, acute tracheitis, acute and chronic bronchitis, bronchial asthma, pleuritis, lung-cardiac insufficiency, bronchoectotic illnesses, and abscesses. It makes the effective treatment of respiratory organs and use of appropriate methods for the illness prevention a relevant issue

One of such methods includes special trainings to strengthen respiratory muscles, to enlarge the mobility of the chest and diaphragm, to increase the elasticity of pleural membranes, to improve the mechanisms of breathing regulation and movement coordination. The depth and frequency of breathing to some extent can be changed voluntarily. It represents a basic breathing training.

Previous work [3] has shown respiratory rate to have powerful physiological effects, for example, on cardiac baroreceptor sensitivity (BRS) independent of direct effects on arterial blood pressure (ABP). Physiological studies have employed various controlled respiratory rates in the spectral 
analysis estimates of, for example, cerebral auto regulation (CA) using 6 breaths/min [4, 5], and cardiac BRS using 15 breaths/min [3]. However, work using the Valsalva and Mueller manoeuvres $[6,7,8]$ has shown that changes in intrathoracic pressure can have a strong influence on the cerebral blood flow velocity (CBFV) response to transient changes in ABP. As the changes in intrathoracic pressure are likely to differ at different breathing rates, we postulate that this may influence estimates of cardiovascular functions.

To date, it is not clear what the effects of synchronized breathing at lower rates might be on cardiovascular functions. Breathing at different frequencies will induce oscillations in ABP that will change the heart work. These considerations led to the main hypothesis of our present study that synchronized breathing at different rates (e.g. 6 breaths/min) will have a significant influence on cardiac functions with results obtained during spontaneous breathing. Eames et al. [9] consider that the rate 6 breaths/min is the most effective.

Different controlled respiratory rates have been used in physiological studies where CA [4, 5] or cardiac BRS [7] have been measured. Disproportionately large changes in CBFV relative to the change in ABP have been recorded during the release phase of the Valsalva manoeuvre [6] and, on a smaller scale, changes in intrathoracic pressure during normal breathing may also add to $\mathrm{CBFV}$ variability on a breath-by-breath basis independent of their effects on ABP. Other sources of CBFV variability could be associated with systemic changes in mean $\mathrm{PaCO}_{2}$ or oxygen tension, central modulating mechanisms, intrinsic cerebral vasomotion or mental activation [10-12]. Controlled respiratory rates might potentially control some of these variables by reducing the randomness of the respiratory effects and by 'clamping' mental activation through concentration on the light-emitting diode.

In other studies, changes thought to reflect impairment of $\mathrm{CA}$ with mean $\mathrm{PaCO}_{2}$ levels have been seen using transfer function and time domain analysis when partial end tidal volume of $\mathrm{CO}_{2}$ increased by $5 \mathrm{mmHg}$ or more $[2,13]$. Coherence function and gain frequency response increased for frequencies below $0.05 \mathrm{~Hz}$, and phase frequency response decreased in the frequency ranges $0.02-0.1 \mathrm{~Hz}$ [2] and $0.07-0.20 \mathrm{~Hz}$ [13]. The coherence functions for the different controlled respiratory frequencies were significantly different from one another at the fundamental respiratory frequencies and their multiple harmonics, and the coherence function for all of the controlled respiration data was periodically higher and lower compared with the data recorded with spontaneous respiration. The observation showed that at 6 breaths $/ \mathrm{min}$, in contrast with the other respiratory frequencies, the peak in coherence at the fundamental frequency was lower than its first harmonic, could be interpreted as a sign of auto regulation in that frequency range that is less effective with increasing frequency.

The effect of phase is incorporated in the time domain measures. The step responses suggested that, in response to a step in ABP, CBFV would subsequently fall towards baseline in slightly less than $5 \mathrm{~s}$ in all recordings, consistent with active CA, as reported from previous observations [14]. The step responses were characteristic of improved CA [14], with decreasing $\mathrm{CO}_{2}$ end tidal volume, associated with the increasing respiratory rate, although the effect of respiratory rate alone was just not significant [4].

It was proposed that during HA adaptation, hypometabolism was developed as a mechanism to cope with the hypoxic stress. Such hypometabolism was also observed in fMRI studies involving gustatory stimulation [15] and cognitive performance [16]. There are also data indicating reduced amount of HA group gray matter volumes at bilateral insula [6] which points to its reduced functionality among the HA group. In authors' opinion one plausible interpretation would be that such reduced functionality contributes to the reduced ventilation associated with long term HA adaptation, in contrast with the hyperventilation typically experienced by new comers.

The goal of our research was to study some peculiarities of respiratory and cardiovascular systems of high altitude residents in Armenia.

\section{Methods}

Participants in the current study included 40 students from Vardenis (Armenia, $2000 \mathrm{~m}$ above the sea level) divided into 2 groups: I - 13-14 years old, and II - 15-17 years old. We have studied the breathing rhythm, chest circumference during quiet and deep breathing, lung vital capacity, erythrocyte amount, hemoglobin concentration, colour index, systolic, diastolic and pulse arterial pressure, before and after trainings. The control groups included 23 students of the same age from Stepanavan $(1300 \mathrm{~m}$ above the sea level). The appropriate parameters were investigated.

The researched students should go through two months of trainings on controlled breathing. During the training the participants should make 6 breathing movements per minute, three times a day. Study of appropriate health parameters was done after the training period.

Significance of received data was determined by statistical analysis through package of SPSS programs (SD $\pm 0.05)$. The entire research was carried out in accordance with Universal Declaration of Bioethics and Human Rights.

\section{Results}

Our data (see table 1) showed significant differences between the control and experimental student groups (see the table). The basal breathing rate in control groups was $16.33 \pm 0.41 \mathrm{breath} / \mathrm{min}$ and $15.09 \pm 0.34 \mathrm{breath} / \mathrm{min}$. In the experimental groups it was respectively $19.25 \pm 0.93(\mathrm{p}<0.05)$ and $23.22 \pm 0.74(\mathrm{p}<0.05)$ breath $/ \mathrm{min}$. So a significantly increased rate of breathing in students from high altitudes was identified. After the training period the breathing rate of students from both experimental groups has significantly decreased to $14.50 \pm 0.54(p<0.05)$ and $16.89 \pm 0.42(p<0.05)$, and became almost the same in comparison with control 
groups.

As the table shows there are significant differences in the erythrocyte amount, and hemoglobin concentration between control and experimental groups. The colour index of control group was within norm and in experimental groups at their minimal level. There are also significant differences in chest circumference during quiet and deep breathing.

The differences of lungs vital capacity in control and experimental groups are not significant, but nevertheless this parameter is too low in the experimental groups. In many cases, the biochemical changes in response to high altitude exposure are so striking that almost everything is statistically significant when compared to baseline. However, uncovering the biological relevance of those alterations remains a challenge. Relatively small (and statistically insignificant) changes in the steady-state concentration of biomarkers and signaling molecules may be associated with biologically significant changes in physiology, in particular when regulatory circuits are operating at their limits. In other cases, statistically significant changes from baseline may simply indicate that the system is operating at a different set point (which may still be well within the regulatory range) [17].

Our data suggest that the bodies of high altitude residents possess mechanisms for adaptation to high altitude, for example high rate of breathing without changes of breathing volume. However the blood hemoglobin saturation is around the normal level, which means that there is also another mechanism underlying the adaptation process.

The students from experimental groups in comparison with students of the same age from the control groups had a significantly higher level of systolic and diastolic, and also pulse pressures, which may suggest the myocardium overloading. After two month of trainings the decrease in systolic and diastolic, and also pulse pressure was identified.

Table 1. Some parameters of pupils living at low (1300 m above the sea level) and high (2000 $\mathrm{m}$ above the sea level) altitudes.

\begin{tabular}{|c|c|c|c|c|}
\hline Investigated parameter & $\begin{array}{c}\text { Number of the } \\
\text { group }\end{array}$ & Contrlol & $\begin{array}{c}\text { Experimental groups before } \\
\text { training }\end{array}$ & $\begin{array}{c}\text { Experimental groups after } \\
\text { training }\end{array}$ \\
\hline \multirow{2}{*}{ Breathing rate (breath/min) } & I & $15.78 \pm 0.36$ & $19.25 \pm 0.93 *$ & $14.50 \pm 0.54^{*}$ \\
\hline & II & $15.09 \pm 0.33$ & $23.22 \pm 0.74^{*}$ & $16.89 \pm 0.42 *$ \\
\hline \multirow{2}{*}{ Erythrocyte amount } & I & $3.75 \times 10^{12} \pm 600.01$ & $4.48 \times 10^{12} \pm 910.07^{*}$ & $4.0 \times 10^{12} \pm 550.05^{*}$ \\
\hline & II & $3.35 \times 10^{12} \pm 270.8$ & $4.36 \times 10^{12} \pm 442.2 *$ & $3.91 \times 10^{12} \pm 300.3^{*}$ \\
\hline \multirow{2}{*}{ Hemoglobin concentration $(\mathrm{g} / \mathrm{l})$} & I & $124.80 \pm 1.16$ & $117.80 \pm 2.25^{*}$ & $133.6 \pm 1.85^{*}$ \\
\hline & II & $125.50 \pm 3.05$ & $113.60 \pm 2.41^{*}$ & $131.2 \pm 2.45^{*}$ \\
\hline \multirow{2}{*}{ Colour index } & I & $1.03 \pm 0.003$ & $0.89 \pm 0.002$ & $1.00 \pm 0.001$ \\
\hline & II & $1.10 \pm 0.005$ & $0.88 \pm 0.003$ & $1.01 \pm 0.002$ \\
\hline \multirow{2}{*}{ Lung vital capacity (ml) } & I & $3200 \pm 160.0$ & $2971.0 \pm 158.4$ & $3614.0 \pm 96.19^{*}$ \\
\hline & II & $3300 \pm 270.0$ & $2662.0 \pm 108.5$ & $4188.0 \pm 246.0^{*}$ \\
\hline \multirow{2}{*}{$\begin{array}{l}\text { Chest circumference during quiet } \\
\text { breathing }(\mathrm{sm})\end{array}$} & I & $70.50 \pm 0.57$ & $73.25 \pm 1.39$ & $73.5 \pm 1.28^{*}$ \\
\hline & II & $79.0 \pm 0.73$ & $83.50 \pm 0.78^{*}$ & $91.0 \pm 1.22 *$ \\
\hline \multirow{2}{*}{$\begin{array}{l}\text { Chest circumference during deep } \\
\text { breathing }(\mathrm{sm})\end{array}$} & I & $75.75 \pm 0.25$ & $81.62 \pm 1.53 *$ & $92.29 \pm 1.55^{*}$ \\
\hline & II & $80.38 \pm 1.19$ & $85.88 \pm 0.70^{*}$ & $94.25 \pm 1.0,8^{*}$ \\
\hline \multirow{2}{*}{ Heart rate (beat/min) } & I & $77.56 \pm 1,19$ & $92.78 \pm 3.06^{*}$ & $75.22 \pm 1.69^{*}$ \\
\hline & II & $78.38 \pm 1.62$ & $91.38 \pm 2.07 *$ & $78.75 \pm 1.85^{*}$ \\
\hline \multirow{2}{*}{ Systolic pressure (mmHg) } & I & $100.0 \pm 2.13$ & $113.60 \pm 1.23^{*}$ & $106.50 \pm 1.13^{*}$ \\
\hline & II & $105.0 \pm 3.27$ & $117.10 \pm 1.97^{*}$ & $105.4 \pm 1.48^{*}$ \\
\hline \multirow{2}{*}{ Diastolic pressure (mmHg) } & I & $55.0 \pm 1.89$ & $61.50 \pm 1.24^{*}$ & $74.12 \pm 0.81 *$ \\
\hline & II & $73.12 \pm 2.82$ & $67.75 \pm 1.36^{*}$ & $77.75 \pm 1.81 *$ \\
\hline \multirow{2}{*}{ Pulse pressure (mmHg) } & I & $40.83 \pm 3.61$ & $51.77 \pm 1.46^{*}$ & $33.38 \pm 1.85^{*}$ \\
\hline & II & $37.72 \pm 1.59$ & $48.91 \pm 2.11^{*}$ & $35.27 \pm 1.17 *$ \\
\hline
\end{tabular}

Medical examination revealed few cases of cardiopulmonary sickness in both experimental groups. 4 of investigated 16 students of the first group had sinus tachycardia, 2 - respiratory arrhythmia, 3 - myocarditis and hypoxia, and 1 - right bundle-branch block.

For 20 investigated students from the second group the following was determined: 2 cases of sinus tachycardia, $1-$ respiratory arrhythmia, 1 - myocarditis and hypoxia, 1 - focal blockade with myocarditis and hypoxia, 1 - right bundle-branch block, and 1 - cardiac rhythm and conduction disturbance.

After the training period in the first group 1 case of respiratory arrhythmia, 1 case of sinus tachycardia was identified with 1 case of myocarditis and hypoxia changed to respiratory arrhythmia. All other students had no deviations. In the second group 1 case of sinus tachycardia 
had changed to sinus arrhythmia, and 1 student had respiratory arrhythmia. So, the trainings on voluntary decrease in breathing rate had a positive effect.
Fig. 1-4 presents the ECG results of four students from two experimental groups before and after training.

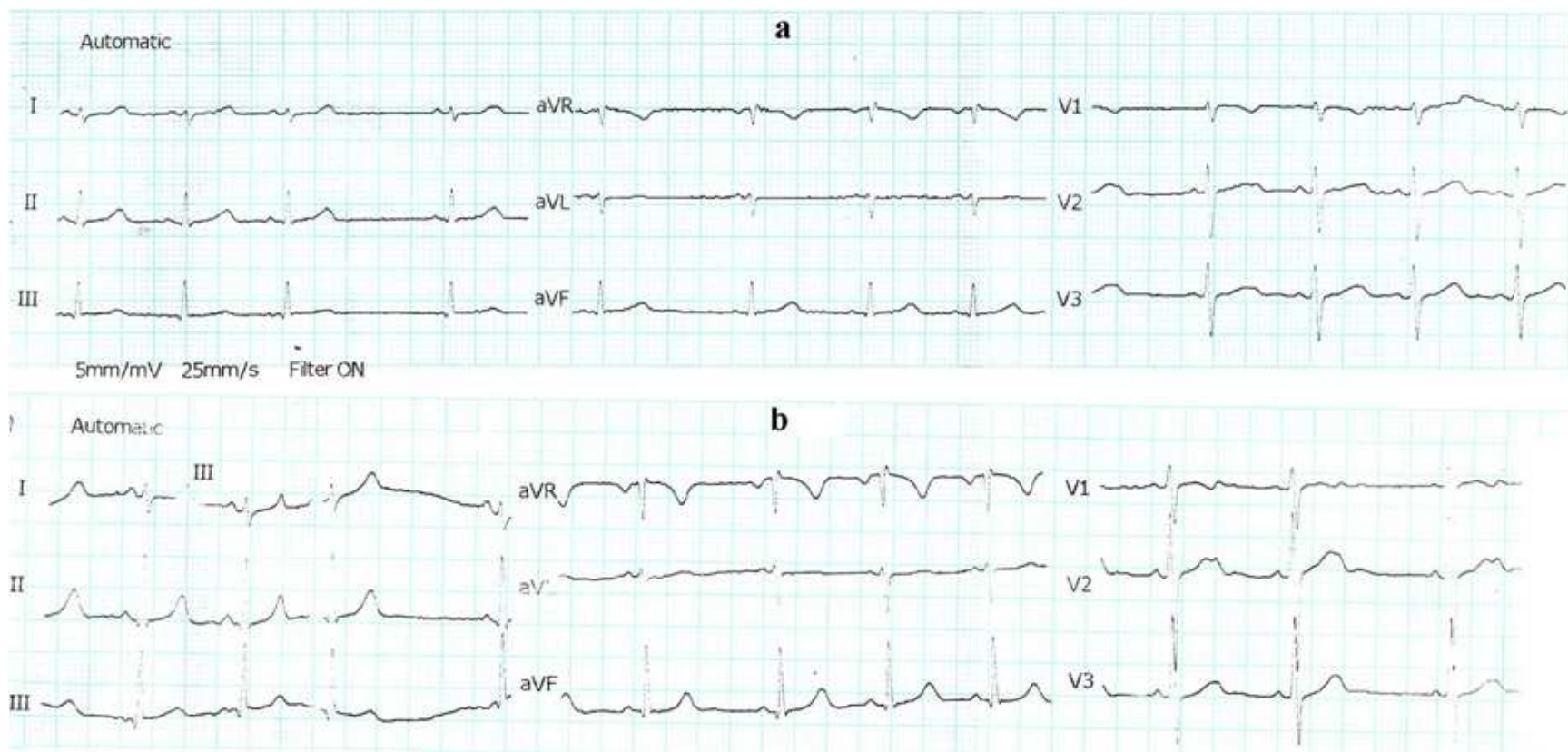

Fig 1. ECG of the patient B.V. (I group). I, II, III, aVR, aVL, aVF, $V_{1}, V_{2}, V_{3}$ - appropriate lead. a - before training (the patient had respiratory arrhythmia), $b$-after training (the patient has no deviations).

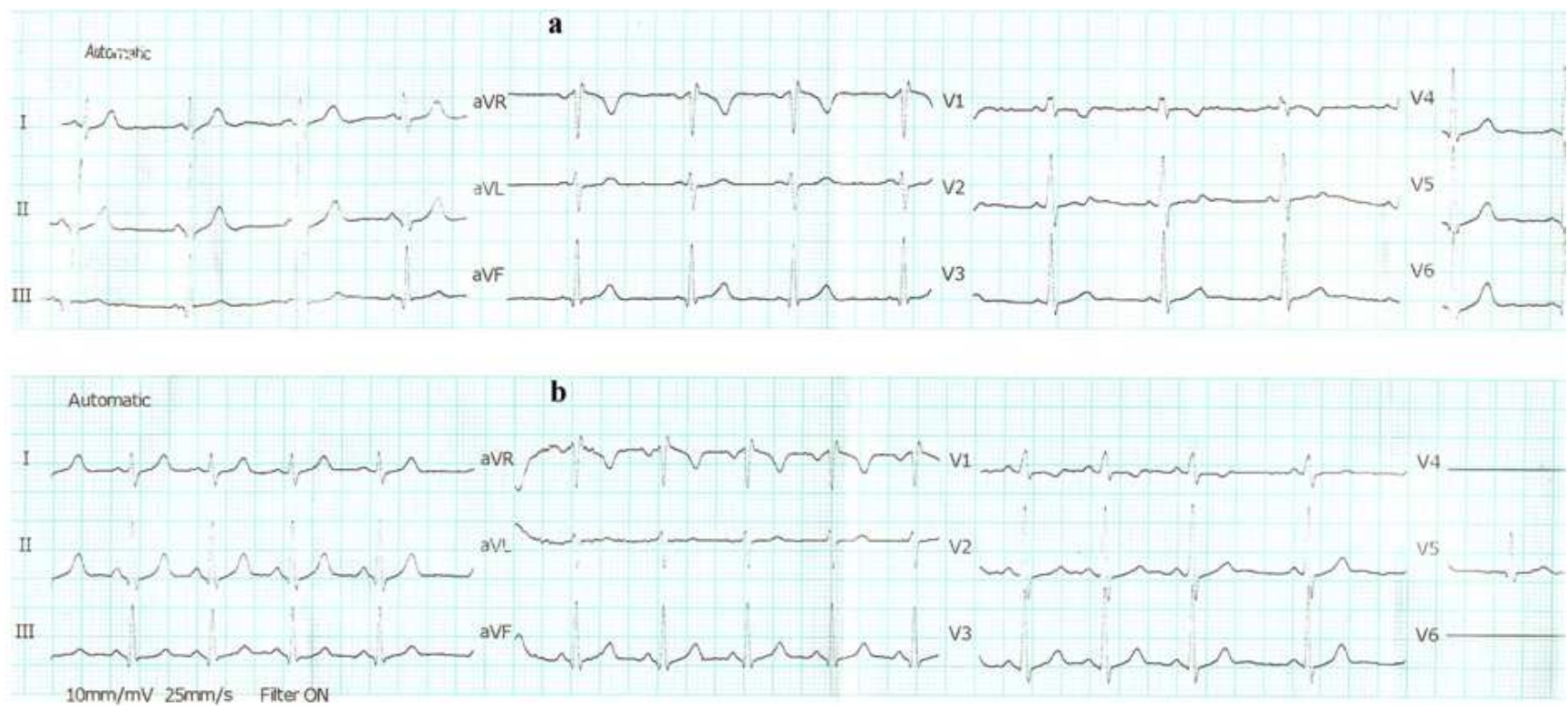

Fig 2. ECG of the patient M.M. (I group). I, II, III, aVR, aVL, aVF, $V_{1}, V_{2}, V_{3}, V_{4}, V_{5}, V_{6}$ - appropriate lead. a - before training (the patient had right bundle-branch block), $b$-after training (the patient has no deviations). 


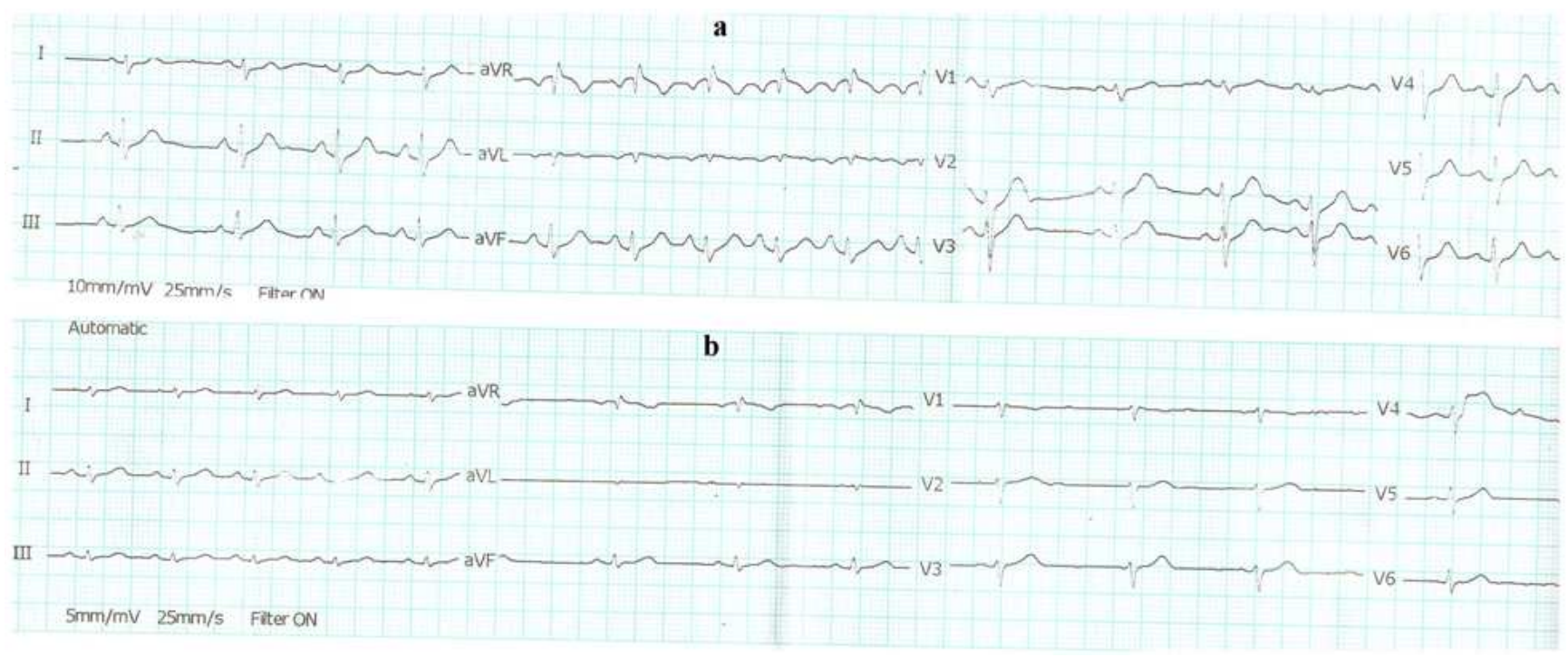

Fig 3. ECG of the patient H.M. (II group). I, II, III, aVR, aVL, aVF, V1,V2, V3, V4, V5, V6-appropriate lead. a - before training (the patient had sinus tachicardia), $b$-after training (the patient has no deviations).

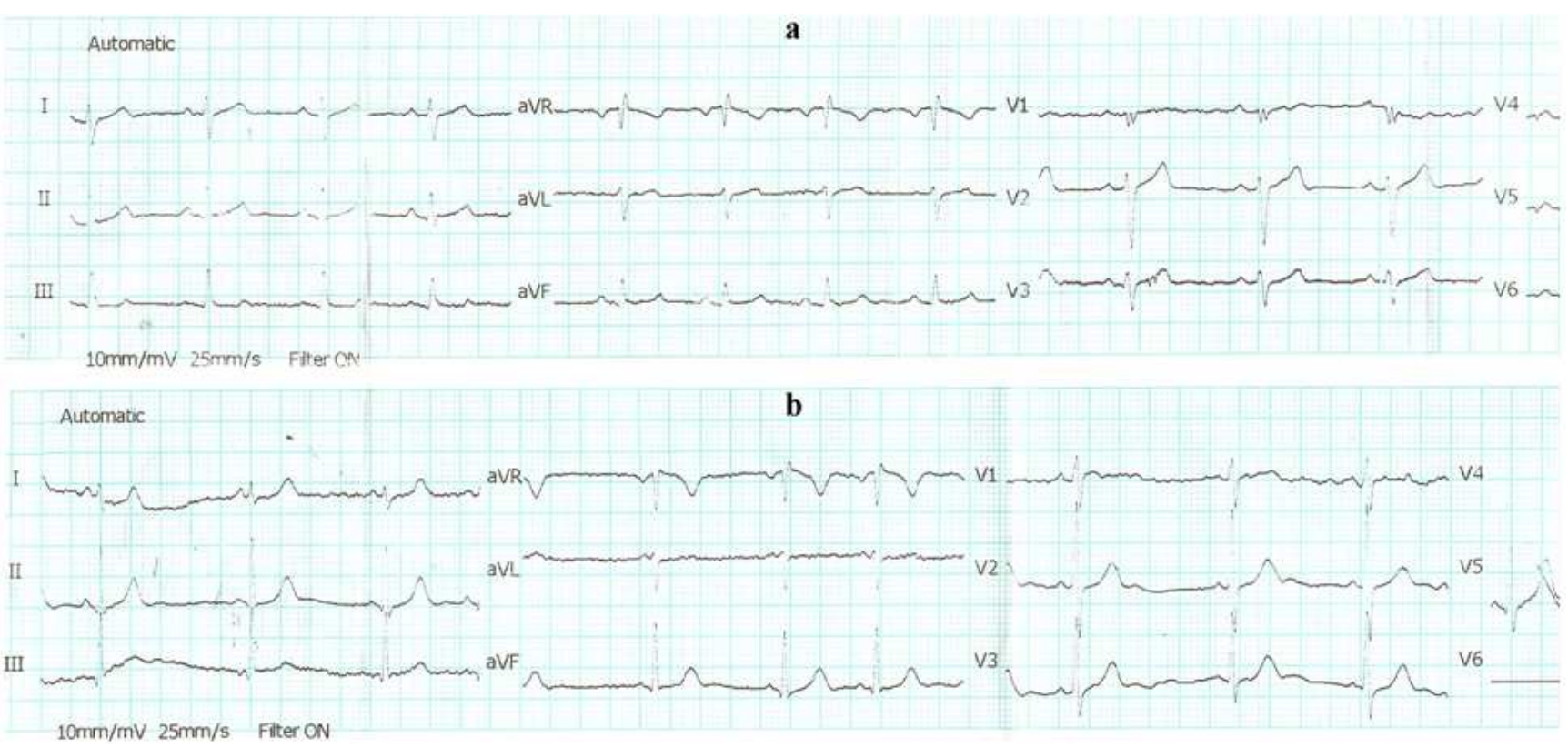

Fig 4. ECG of the patient M.V. (II group). I, II, III, aVR, aVL, aVF, V1,V2, V3, V4, V5, V6-appropriate lead. a - before training (the patient had right bundle-branch block), $b$ - after training (the patient has no deviations).

\section{Discussion}

Barometric pressure falls with increasing altitude whilst the percentage of oxygen within the atmosphere remains constant. The consequent reduction in inspired oxygen impairs physical performance and may even threaten survival [18]. Graded and continued altitude exposure permits acclimatization, a progressive tolerance to hypoxia traditionally ascribed to cardiopulmonary and hematological responses that support global convective oxygen delivery [19]. These changes tend to reduce the gradient of oxygen partial pressure from ambient air to tissues [20] by increase of erythrocytes amount, systolic volume and hemoglobin concentration, which was shown also in our studies. It was reported that peripheral physiological parameters, especially hemoglobin concentration, adapt very quickly to hypoxia/normoxia changes in the scale of weeks [21].

However, such responses do not provide a full explanation of the acclimatization process given that exercise tolerance remains limited even though arterial oxygen content returns to sea-level values [22, 23]. Furthermore, genetic selection pressure amongst high-altitude residents of the Tibetan Plateau (in situ for $>20,000$ years) favours lower rather than higher levels of oxygen-carrying hemoglobin [24, 25]. Finally, the marked inter-individual differences which exist in the ability to adapt to hypoxia sometimes are not explained by differences in arterial oxygen content [22]. Changes in 
tissue oxygen handling, mediated in part through changes in the microcirculation and in mitochondrial oxygen use, are increasingly considered more important to the development of hypoxia tolerance than is the augmentation of its global convective delivery [23, 26, 27].

Significant correlations were found between specific aspects of pulmonary function (IRV \& ERV) and BOLD signal variation at specific brain regions [28]. These correlations indicate the contribution of specific aspects of pulmonary function to cerebrovascular response (CVR). It seems that IRV had a wide influence on BOLD signal across multiple brain regions, not only in cortices involved in respiratory modulation (e.g., the insula, thalamus, and the precentral cortex), but also other cortices such as the fusiform cortex. The HA group indeed showed a larger IRV than the control group, while other aspects of pulmonary function maintained at a similar level [28]. In authors' opinion, it could be possible that it took a longer time for the oxygenation level of the HA group to reach peak, considering that the HA group had similar levels of respiration rate and hemoglobin concentration with the only observed difference at IRV; and this delay was eventually reflected in the delay of BOLD signal. It could also be related to the involvement of these brain regions in respiratory modulation.

As the study of a numbers shows, adaptation to high altitude describes changes that have occurred over a number of generations as a result of natural selection in a hypobaric hypoxic environment, and this can be observed in some groups of high-altitude residents [29]. The mechanisms responsible for such adaptation probably involve alterations in the control of breathing [30, 31].

It's known that the cardiovascular responses to voluntary delay of breathing are defined by interaction of different reflexes between lung vessels and mechano- and chemoreceptors of reflexogenic zones [3, 32]. Significant role in these interactions have changes of pressure in lungs, chest and abdominal cavity, which influences at the venous flow into the heart, and arterial pressure during breathing delay. Delayed deep breathing decreases the pressure in the chest and facilitates venous flow to the heart. Besides the accumulation of carbon dioxide in organism during breathing delay leads to extension of coronary vessels, and therefore improves myocardium delivering.

After controlled breathing trainings all investigated parameters became comparable with the same parameters of the control group. Therefore the method of voluntary decrease in the breathing rate is effective for the students living at high altitudes. Obviously after breathing trainings the adaptive mechanisms of metabolism and activity of aerobic breathing ferments are changed, which lead to the new level of oxygen delivery, and consequently to changes of oxygen delivering organs and systems. It is confirmed by positive correlation of breathing with decrease in sickness, improvement in heart work, physical and mental capacities. Practically the volitional control of breathing leads to positive changes in cardiovascular system. In summary, our results suggest the possible contributions of pulmonary functions in cardiovascular reaction.

Vardenis region lies at $2000 \mathrm{~m}$ above the sea level (atmosphere pressure $809.92 \mathrm{mbar}$ ): It is important to note that today Vardenis out-patient clinic has 468 patients registered with ischemic heart disease, 678 patients with hypertension, 60 patients with acute bronchitis, and 29 patients with bronchial asthma. Most probably there are more unregistered people with arterial blood pressure oscillations.

The control of breathing can be divided into chemoreflex and non-chemoreflex drives to breathe. Non-chemoreflex drives (e.g. wakefulness drive, voluntary cortical drive, hormonal factors) have never been measured in highlanders, while a single study of acclimatization in lowlanders showed that these drives remain unchanged from sea-level values after 5 days of high altitude exposure [33]. Chemoreflex drives to breathe can be further divided into central and peripheral drives. Both central and peripheral chemoreceptors respond to changes in hydrogen ion concentration $\left(\left[\mathrm{H}^{+}\right]\right)$in their immediate environments $[34$, 35], while peripheral chemoreceptors are also responsive to changes in $\mathrm{PO}_{2}$ via hypoxia-mediated changes in their $\left[\mathrm{H}^{+}\right]$ ion sensitivity [36, 37]. As a result, highlanders have induced acute changes in $\mathrm{PO}_{2}$ and $\mathrm{PCO}_{2}$ and measured the ensuing changes in ventilation to assess the chemoreflex control of breathing [38].

\section{Conclusion}

The cardiovascular system is an essential link in the transport of oxygen from the air to the mitochondria, and it therefore has an important role in acclimatization and adaptation to the oxygen depleted environment of high altitude. Using of the method voluntary optimal changes in breathing rate it may be possible to improve the adaptive mechanisms of high altitude residents, and health of patients with cardiovascular diseases.

\section{References}

[1] Biswal B.B., Kylen J.V., Hyde J.S. Simultaneous assessment of flow and BOLD signals in resting-state functional connectivity maps. NMR Biomed., 1997, 10 (45): 165-170.

[2] Panerai R. B., Deverson S. T., Mahony P. J., Hayes P. D., Evans D. H. Effect of $\mathrm{CO}_{2}$ on dynamic cerebral autoregulation measurement. Physiol. Meas., 1999, 20: 265-275.

[3] Frederiks J., Swenne C. A., TenVoorde B. J., Honzikova N., Levert J.V., Maan A.C., Schalij M.J., Bruschke A.V. The importance of high-frequency paced breathing in spectral baroreflex sensitivity assessment. J. Hypertens., 2000, 18: $1635-1644$.

[4] Diehl R. R., Linden D., Lucke D., Berlit P. Phase relationship between cerebral blood flow velocity and blood pressure. A clinical test of cerebral autoregulation. Stroke, 1995, 26: 1801-1804. 
[5] Reinhard M., Muller T., Guschlbauer B., Timmer J., Hetzel A. Transfer function analysis for clinical evaluation of dynamic cerebral autoregulation: a comparison between spontaneous and respiratory induced oscillations. Physiol. Meas., 2003, 24: 27-43.

[6] Dawson S. L., Panerai R. B., Potter J. F. Critical closing pressure explains cerebral haemodynamics during the Valsalva maneuver. J. Appl. Physiol., 1999, 86: 675-680.

[7] Reinhard M., Hetzel A., Hinkov V., Lucking C. H. Cerebral haemodynamics during the Mueller maneuver in humans. Clin. Physiol., 2000, 20: 292-303.

[8] Tiecks F. P., Haberl R. L., Newell D. W. Temporal patterns of evoked cerebral blood flow during reading. J. Cereb. Blood Flow Metab., 1998, 18: 735-741.

[9] Eames P. J., Potter J. F., Panerai R. B. Influence of controlled breathing patterns on cerebrovascular autoregulation and cardiac baroreceptor sensitivity. Clinical Science, 2004, 106: 155-162. (Printed in Great Britain).

[10] Kelley R. E., Chang J. Y., Scheinman N. J., Levin B. E., Duncan R. C., Lee S.-C. Transcranial Doppler assessment of cerebral flow velocity during cognitive tasks. Stroke, 1992, 23: 9-14.

[11] Silvestrini M., Troisi E., Matteis M., Razzano C., Caltagirone C. Correlations of flow velocity changes during mental activity and recovery from aphasia in ischaemic stroke. Neurology, 1998, 50: 191-195.

[12] Tiecks F. P., Lam A. M., Matta B. F., Strebel S., Douville C. M., Newell D. W. Effects of the valsalva maneuver on cerebral circulation in healthy adults. A transcranial Doppler study. Stroke, 1995, 26: 1386-1392.

[13] Zhang R., Zuckerman J.H., Giller C.A., Levine B.D. Transfer function analysis of dynamic cerebral auto regulation in humans. Am. J. Physiol., 1998, 43: H233-H241.

[14] Panerai R. B., Rennie J. M., Kelsall A. W. R., Evans D. H. Frequency-domain analysis of cerebral autoregulation from spontaneous fluctuations in arterial blood pressure. Med. Biol. Eng. Comput., 1998, 36: 315-322.

[15] Jansen G.F.A., Krins A., Basnyat B., Bosch A., Odoom J.A. Cerebral autoregulation in subjects adapted and not adapted to high altitude. Stroke, 2000, 31(10): 2314-2318.

[16] Ackermann H., Riecker A. The contribution (s) of the insula to speech production: a review of the clinical and functional imaging literature. Brain Structure and Function, 2010, 214: 419-433.

[17] Levett D. Z., Fernandez B. O., Riley H. L., Martin D. S., Mitchell K., Leckstrom C.A., Ince C., Whipp B.J., Mythen M.G., Montgomery H.E., Grocott M.P., Feelisch M., and for the Caudwell Extreme Everest Research Group. The role of nitrogen oxides in human adaptation to hypoxia. Sci. Rep., 2011, 1: 109 .

[18] Penaloza D., Arias-Stella J. The heart and pulmonary circulation at high altitudes: healthy highlanders and chronic mountain sickness. Circulation, 2007, 115: 1132-1146.

[19] West J. B., Schoene R. B., Milledge J. S. High Altitude Medicine and Physiology. $4^{\text {th }}$ edition. London: Hodder Arnold, 2007: 499 p.
[20] Ward M.P., Milledge J.S., West J.B. Acute and subacute mountain sickness. In: Ward et al. High Altitude Medicine and Physiology. London: Chapman \& Hall Medical, 1995: 366-387.

[21] Neubauer J.A. Physiological and Genomic Consequences of Intermittent Hypoxia: Invited Review: Physiological and pathophysiological responses to intermittent hypoxia. $J$. Appl. Physiol. 2001, 90 (4): 1593-1599.

[22] Calbet J. A., Boushel R., Radegran G., Sondergaard H., Wagner P.D., Saltin B. Why is $\mathrm{VO}_{2}$ max after altitude acclimatization still reduced despite normalization of arterial $\mathrm{O}_{2}$ content? Am. J. Physiol. Regul. Integr. Comp. Physiol., 2003, 284: R304-R316.

[23] Grocott M., Montgomery H., Vercueil A. High-altitude physiology and pathophysiology: implications and relevance for intensive care medicine. Crit. Care, 2007, 11: 203.

[24] Beall C.M., Cavalleri G.L., Deng L., Elston R.C., Yang Gao, Jo Knight, Chaohua Li, Jiang Chuan Li, Yu Liang, Mark McCormack, Hugh E. Montgomery, Hao Pan. Natural selection on EPAS1 (HIF2alpha) associated with low hemoglobin concentration in Tibetan highlanders. Proc. Natl. Acad. Sci. USA, 2010, 107: 11459-11464.

[25] Yi X., Liang Y., Huerta-Sanchez E., Jin X., Cuo Z.X., Pool J.E., $\mathrm{Xu}$ X., Jiang H., Vinckenbosch N., Korneliussen T.S., Zheng H., Liu T., He W., Li K., Luo R., Nie X., Wu H., Zhao M., Cao H., Zou J., Shan Y., Li S., Yang Q., Ni P., Tian G., Xu J., Liu X., Jiang T., Wu R., Zhou G., Tang M., Qin J., Wang T., Feng S., Li G., Luosang J., Wang W., Chen F., Wang Y., Zheng X., Li Z., Bianba Z., Yang G., Wang X., Tang S., Gao G., Chen Y., Luo Z., Gusang L., Cao Z., Zhang Q., Ouyang W., Ren X., Liang H., Huang Y., Li J., Bolund L., Kristiansen K., Li Y., Y. Zhang, Zhang X., Li R., Yang H., Nielsen R., Wang J. Sequencing of 50 human exomes reveals adaptation to high altitude. Science, 2010, 329: 75-78.

[26] Aragones J., Schneider M., Van Geytel K., Fraisl P., Dresselaers T., Mazzone M., Dirkx R., Zacchigna S., Lemieux H., Jeoung N.H., Lambrechts D., Bishop T., Lafuste P., Diez-Juan A., K. Harten S., Van Noten P., De Bock K.,Willam C., Tjwa M., Grosfeld A., Navet R., Moons L., Vandendriessche T., Deroose C., Wijeyekoon B., Nuyts J., Jordan B., Silasi-Mansat R., Lupu F., Dewerchin M., Pugh C., Salmon P., Mortelmans L., Gallez B., Gorus F., Buyse J., Sluse F., Harris R.A., Gnaiger E., Hespel P., Van Hecke P., Schuit F., Van Veldhoven P., Ratcliffe P., Baes M., Maxwell P., Carmeliet P. Deficiency or inhibition of oxygen sensor Phd1 induces hypoxia tolerance by reprogramming basal metabolism. Nat. Genet., 2008, 40: 170-180.

[27] Levett D. Z., Martin D. S., Wilson M. H., Mitchell K.D., Sundeep R.F., Montgomery H.E., Mythen M. and Grocott M. P. W. Design and conduct of Caudwell Xtreme Everest: an observational cohort study of variation in human adaptation to progressive environmental hypoxia. BMC Med. Res. Methodol., 2010, 10: 98.

[28] Yan X., Zhang J., Gong Q., Weng X. Cerebrovascular reactivity among native-raised high altitude residents: an fMRI study. BMC Neurosci. 2011, 12: 94.

[29] Grocott M. B., Martin D. S., Levett D. Z., McMorrow R., Windsor J., Montgomery H. Arterial blood gases and 
oxygen content in climbers on Mount Everest. N. Engl. J. Med., 2009, 360: 140-149.

[30] Brutsaert T.D. Population genetic aspects and phenotypic plasticity of ventilatory responses in high altitude natives. Respir. Physiol. Neurobiol., 2007, 158: 151-160.

[31] Moore L.G. Comparative human ventilatory adaptation to high altitude. Respir. Physiol., 2000, 121 (2-3): 257-276.

[32] Tiinanen S., Tulppo M., Seppänen T. Reducing the effect of respiration in baroreflex sensitivity estimation with adaptive filtering. IEEE Trans. Biomed. Eng., 2008, 55 (1): 51-59.

[33] Somogyi R.B., Preiss D., Vesely A., Fisher J.A., Duffin J. Changes in respiratory control after 5 days at altitude. Respir. Physiol. Neurobiol., 2005, 145: 41-52.
[34] Nattie E., Li A. Central chemoreception is a complex system function that involves multiple brain stem sites. J. Appl. Physiol., 2009, 106: 1464-1466.

[35] Torrance R.W. Prolegomena. Chemoreception upstream of transmitters. Adv. Exp. Med. Biol., 1996, 410: 13-38.

[36] Kumar P., Bin-Jaliah I. Adequate stimuli of the carotid body: more than an oxygen sensor? Respir. Physiol. Neurobiol., 2007, 157: 12-21.

[37] Torrance R.W. Kumar P., Bin-Jaliah I. Adequate stimuli of the carotid body: more than an oxygen sensor? Respir. Physiol. Neuroiol., 2007, 157: 12-21.

[38] Duffin J. Measuring the ventilatory response to hypoxia. $J$. Physiol., 2007, 584: 285-293 